\title{
The Integration of Social Concerns into Electricity Power Planning: A Combined Delphi and AHP Approach
}

\author{
P. Ferreira, M. Araújo, and M.E.J. O’Kelly
}

\begin{abstract}
The increasing acceptance of the principle of sustainable development has been a major driving force towards new approaches to energy planning. This is a complex process involving multiple and conflicting objectives, in which many agents were able to influence decisions. The integration of environmental, social and economic issues in decision making, although fundamental, is not an easy task, and tradeoffs must be made. The increasing importance of social aspects adds additional complexity to the traditional models that must now deal with variables recognizably difficult to measure in a quantitative scale. This study explores the issue of the social impact, as a fundamental aspect of the electricity planning process, aiming to give a measurable interpretation of the expected social impact of future electricity scenarios. A structured methodology, based on a combination of the Analytic Hierarchy Process and Delphi process, is proposed. The methodology is applied for the social evaluation of future electricity scenarios in Portugal, resulting in the elicitation and assignment of average social impact values for these scenarios. The proposed tool offers guidance to decision makers and presents a clear path to explicitly recognise and integrate the social preferences into electricity planning models.
\end{abstract}

Keywords Analytic Hierarchy Process (AHP) - Delphi · Electricity power planning $\cdot$ Social impact $\cdot$ Social sustainability

\section{Introduction}

Sustainable long-range electricity planning involves tradeoffs between multiple goals. Rationally, the multiple attributes of each competing and acceptable electricity generation technology or portfolio, in terms of the attainment of goals, must be

P. Ferreira $(\bowtie)$

Department of Production and Systems, University of Minho, Azurem, 4800-058 Guimarães Portugal

e-mail: paulaf@dps.uminho.pt 
assessed. Integrated resource planning should seek to identify the mix of resources that can best meet the future electricity needs of consumers, the economy, the environment and the society.

Environmental impacts of electricity generation activities become increasingly critical. The need to control atmospheric emissions of greenhouse and other gases and substances requires the full evaluation of the environmental characteristics of each electricity generation technology and the inclusion of environmental objectives in the electricity planning process. Cost minimisation is also perceived as fundamental to ensure the competitiveness of the economy. Attaining this objective involves the careful selection of technologies and efficient management of the system operation and power reserve requirements. Long-term electricity planning frequently relies on complex optimisation models drawn to minimise cost, restricted by technical and environmental conditions.

The complexity of the problem increased further due to the desirable inclusion of a number of unquantifiable or subjectively valued objectives, thus making energy planning decisions prone to some degree of controversy. For example, renewable energy projects, and in particular wind power plants, frequently have to face local opposition, and the spread of these renewable technologies may be slowed down by low social acceptability. The electricity planning process needs to rely on a formal approach for the assessment of the overall social outcome of each particular generation mix. This work addresses this matter and deals with the complexity of the social issues surrounding electricity planning, providing guidance on how to integrate the social dimension into the development of sustainable electricity plans for the future.

The structure of this paper is presented subsequently. Following this introduction, Sect. 2 aims to bring a theoretical background to the study. The close relationship between sustainable development and energy is described. The integration of sustainable development concerns into energy planning is examined, addressing in particular the social dimension of the problem. In Sect. 3 a structured methodology is proposed to assess the social sustainability of different electricity generation technologies, aiming to incorporate this information into the overall electricity planning process. Section 4 deals with the application of the proposed methodology to the case of sustainable electricity planning in Portugal. The main conclusions are summarised in Sect. 5, pointing out also directions for further research.

\section{Energy and Sustainable Development}

Energy use and availability are central issues in sustainable development. Energy is essential for economic development and for improving society's living standards. However, political decisions regarding the use of sustainable energy must take into account social and environmental concerns. Until recently, sustainable development was perceived as an essential environmental issue, concerning the integration of environmental concerns into economic decision-making (Lehtonen 2004). For example, for the particular case of the role of renewable energy sources (RES) to 
sustainable development, Del Río and Burguillo (2008) support the view that much emphasis is being put on the environmental benefits, while socioeconomic impacts have not received a comparable attention.

The three dimensions of sustainable development are intrinsically linked. As the G8 Renewable Energy Task Force (2001) [p. 14] recognises: "Economies can only grow if they are not threatened by environmental catastrophe or social unrest. Environmental quality can only be protected if basic economic needs are fulfilled and individuals take responsibility for public goods. Finally, social development rests on economic growth as well as a healthy environment." The economic, social and environmental perspectives are all included in the key elements of a sustainable energy system listed by Jefferson (2006): sufficient growth of energy supplies to meet human needs, energy efficiency and conservation measures, addressing public health and safety issues and protection of the biosphere. Thus, the sustainable development and sustainable energy planning are based on the same three dimensions, viz., economic, environmental and social.

The increasing acceptance of the principle of sustainable development has been a major driving force towards new approaches to energy planning. Achieving the goal of sustainable development implies recognising and including the social and environmental impacts of the energy sector in the decision making process. Under conditions of sustainable energy planning, the profitability of energy companies and the financial viability of energy projects become highly dependent on non-financial factors. The simultaneous assessment of economic, strategic, social, environmental and technical aspects is fundamental for making professionally correct investment decisions in any sector. ${ }^{1}$ However, it is particularly important for the energy sector, traditionally associated with large-scale projects with strong and conflicting social impacts: on the one hand, these projects are absolutely indispensable for the social welfare of the population, but on the other hand, they are frequently associated with environmental problems and have to deal with social opposition.

The evaluation of technologies and future scenarios needs to expand beyond financial cost alone and the appraisal process must be based on a framework recognising full social cost. Proper selection of energy technologies for the future represents a valuable contribution to meeting sustainable energy development targets. Hepbasli (2008) states that energy resources and their utilisation is intimately related to sustainable development and a sustainable energy system must fulfil the requirements of being cost-efficient, reliable and environmental friendly. Also Dincer and Rosen (2005) state that sustainable development requires a sustainable supply of clean and affordable energy resources that do not cause negative societal impacts. Similarly, Lund (2007) supports the view that sustainable development involves energy savings on the demand side, efficiency improvements in the energy production and replacement of fossil fuels by various sources of renewable energy.

\footnotetext{
${ }^{1}$ The inclusion of non-financial aspects in project evaluation is debated at some length in a previous work from the authors (Ferreira et al. 2004).
} 


\subsection{Sustainable Energy Planning}

Electricity power planning is, using the definition of Hobbs (1995) [p. 1], "the selection of power generation and energy efficiency resources to meet customer demands for electricity over a multi-decade time horizon". This author presents three reasons for the increased complexity of the energy planning process: the increasing number of options; the great uncertainty in load growth, fuel markets, technological development and government regulation; and finally, the inclusion of new objectives other than cost. In fact, the changes in the electricity sector along with the need for sustainable development required traditional electricity planning to expand beyond pure financial analysis and even beyond direct environmental impact analysis. The increasing use of RES in electricity systems adds additional considerations to the traditional planning models, in particular the need to take into account (a) their frequent priority access to the grid system, (b) the impacts that technologies of variable output such as wind energy can have on the overall operation of the electricity system and (c) the public attitude towards these technologies. In addition, the central electricity planning process based on a single decision maker is no longer acceptable, and the importance of examining tradeoffs amongst objectives is now well recognised. Considering the three dimensions of sustainable development has gradually increased the importance of the social aspect in the decision process.

The energy planner has now the task of designing electricity strategies for the future, with the view of enhancing the financial performance of the sector while simultaneously addressing environmental and social concerns. Thus, the planners must deal not only with variables that may be quantified and simulated but also with the social impact assessment. As Bruckner et al. (2005) note, this is an ever changing field depending on aspects like policy issues, advances in computer sciences and developments in economics, engineering and sociology.

The electricity planning process has been addressed by a large number of authors, proposing different approaches and methods to solve these problems. Most of these approaches include diverse multicriteria tools, expressing each criterion in its own units or involving some kind of cost benefit analysis, in which environmental criteria are expressed in economic terms. The process frequently requires the planner to work with quantitative and qualitative information. However, continuous models focus mainly on the cost and economic dimensions of the problem. Some of the less quantifiable issues associated with the social impacts of electricity generating activities have been covered by multicriteria methods, using well recognised methods like the ones from the outranking family such as the Analytic Hierarchy Process (AHP), or by the economic valuation of externalities like the ExternE study (European Commission 2003).

The literature, for long, has been debating the planning methods available and providing some examples of the application. A detailed analysis of the subject may be found in studies such as Loring (2007) or Pohekar and Ramachandran (2004), where the authors review a large number of publications on the use of multicriteria decision making for energy planning. Also Hobbs and Meier (2003), [p. 123] present what they call a "representative sample" of multicriteria decision making 
applications to energy planning and policy problems. Huang et al. (1995) present a comprehensive literature review on decision analysis on energy and environmental modelling, including studies published from 1960 to 1994. Greening and Bernow (2004) collect some examples describing the application of several multicriteria methods to energy and environmental issues. Diakoulaki et al. (2005) analysed a large number of publications addressing the use of multicriteria methods to energy related decisions and Jebaraj and Iniyan (2006) review several energy models, including planning and optimisation models, among others. ${ }^{2}$

\subsection{Importance of the Social Dimension}

The thinking about social sustainability is not yet as advanced as for the other two pillars (World Bank 2003). However, the Brundtland Report (World Commission on Environment and Development 1987) made clear the need to expand the sustainable development concept beyond ecological concerns and fully recognise and integrate the social dimensions of sustainability, reflecting the need to ensure equitable social progress and overall social welfare. Recent studies involving energy indicators for sustainable development already reveal increasing concern with the social dimension of the concept, especially for developing countries, as in Pereira et al. (2007) or Vera and Langlois (2007).

The question of public acceptance is now generally viewed as a fundamental aspect to be included in the social dimension of the sustainable energy planning process, frequently addressed by participatory methods. Energy planning often involves many decision makers and can affect numerous and heterogeneous stakeholders, with different value systems and different concerns (Greening and Bernow 2004). Because of the great variety of ethical positions, the perception of the stakeholders involved may differ significantly.

The consultation of relevant experts and competent authorities is an essential element in the decision process, and multicriteria applications frequently involve a large and interdisciplinary group of stakeholders (Diakoulaki et al. 2005). The World Commission on Dams (2001) underlines the need to implement participatory decision-making for improving the outcome of dams and water development projects and points, gaining public acceptance as a strategic priority of the projects. Del Río and Burguillo (2008) stressed the importance of the participatory approach which takes into account the opinions and interests of all stakeholders. The authors argued that the assessment of a project's sustainability should focus not only on the impact of the proposal, but also on how this impact is perceived by the local population, how the benefits are distributed among the different players and how this perception and distribution affects the acceptance of the project. In conclusion, the acceptance or rejection of a renewable energy project by the local population can

\footnotetext{
${ }^{2}$ A review of recent papers proposing different approaches to energy planning, with predominant emphasis on the particular sector of electricity, may be found in Ferreira (2008), Chap. 3.
} 
make its implementation and its contribution to local sustainability either a success or a failure. Loring (2007) analysed the factors affecting wind energy projects' success and concluded that projects with high levels of participatory planning are more likely to be publicly accepted and successful. Also Wolsink (2007) drew attention to the need to take into consideration public attitude on wind implementation decisions, not only at a general level but also at the local project level, and stressed the importance of including the public in the decision making process.

The creation of clear energy strategies merging cost effectiveness with environmental and social issues is the main challenge for energy planners. Cost oriented approaches, where the monetary assessment is the only basis for the decision making, are no longer an option, and information on the ecological and social impacts of the possible energy plans need to be combined with traditional economic monetary indicators. The existence of different perspectives and values must also be acknowledged and fully incorporated in the planning process, avoiding centralised decisions based on restricted judgements. The evolution of the market conditions and the increasing concerns with sustainable development have brought about profound changes in the approach to the energy decision process and to the priority assigned to each objective during the energy planning process. Sustainable energy planning should now be seen as a multidisciplinary process, where the economic, environmental and social impacts must be taken into consideration, at local and global levels, and where the participatory approaches can bring considerable benefits.

As highlighted by Söderholm and Sundqvist (2003), many impacts of the power generation sector involve moral concerns, and economic valuation provides an insufficient basis for social choice. The social dimension of sustainable development is much more elusive and recognizably difficult to analyse quantitatively. Thus, the social analysis cannot be addressed with the same analytic toolbox as the environment and economic ones (Lehtonen 2004). This study explores the issue of the social impact as a fundamental aspect of the electricity planning process, with strong implications for the policy decision making and for the effective realisation of the drawn plans. A structured methodology is presented, establishing a possible way of quantifying the expected overall social impact of future electricity generation scenarios.

\section{Methodology}

The core elements of the proposed methodology are the Delphi survey and the AHP analysis. By subdividing the problem into its constituent parts (Analytic Hierarchy), the problem is simplified and allows information on each separate issue to be examined. The relative strength or priority of each objective can be established (Delphi process) and the results synthesised to derive a single overall priority for all activities (Hemphill et al. 2002).

The combination of the AHP and Delphi has been used in different fields, with the aim of quantifying the value judgment obtained in a group decision-making 


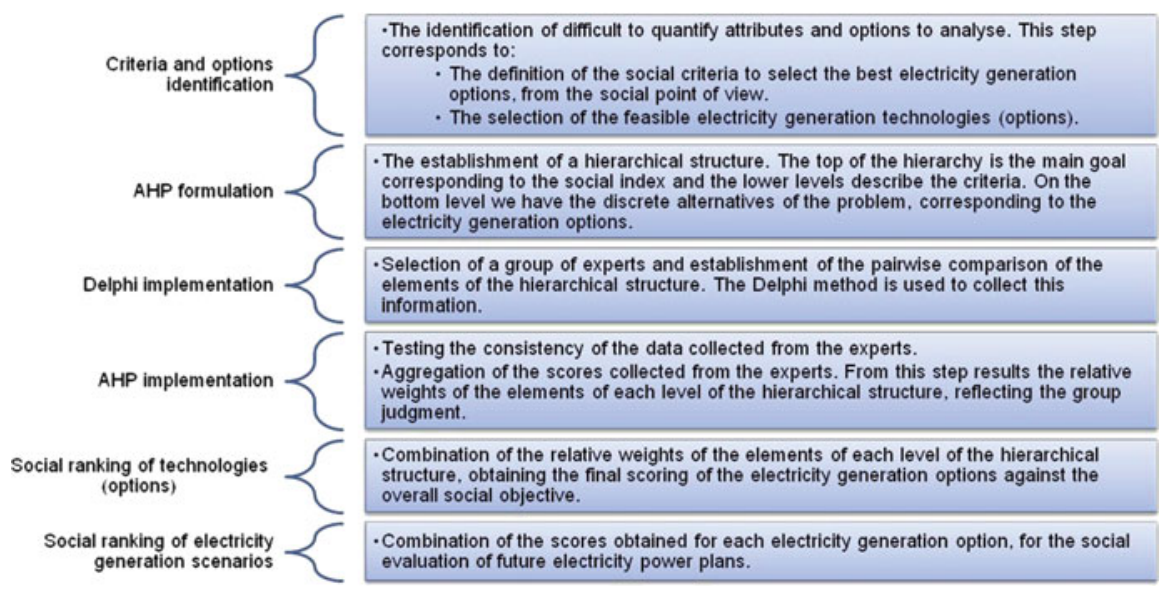

Fig. 1 Proposed methodology for integrating social concerns into an electricity power planning

process. Some recent examples include works from Hemphill et al. (2002), on the weighting of the key attributes of sustainable urban regeneration, or Zhong-Wu et al. (2007), for the appraisal of the eco-environmental quality of an ecosystem. Liang et al. (2006) presented a power generation expansion model that uses AHP and Delphi methodologies, and more recently Torres Sibille et al. (2009a,b) applied these methods on the definition of an indicator for the quantification of the objective aesthetic impact of solar power plants and wind farms.

The proposed methodology for establishing a possible way of allocating weights to the major social impacts and resulting in a final social impact index for future electricity power plans or scenarios is shown in Fig. 1.

\subsection{Suitability of the AHP Approach}

The analytical hierarchy process was developed by Saaty (1980) and is based on the formulation of the decision problem in a hierarchical structure. Typically, the overall objective or goal of the decision-making process is represented at the top level, criterion or attribute elements affecting the decision at the intermediate level and the decision options at the lower level (Nigim et al. 2004). The user chooses weights by comparing attributes two at a time, assessing the ratios for their importance. These ratios are used not only to compute the weights of individual attributes, but also to measure the consistency of the user's assessments (Hobbs and Meier 2003). The method incorporates the researcher's subjective judgment aided, if needs be, by expert opinion during the analysis and by expressing the complex system in a hierarchical structure. Thus, AHP assists the decision-making process to be systemic, numerical and computable. 
AHP is a popular method in problem evaluation (see, e.g., Hobbs and Meier (2003), Limmeechokchaia and Chawana (2007) or Liang et al. (2006)). It is recognized as a robust and flexible tool for dealing with complex decision-making problems (Liang et al. 2006) and its use has been largely explored in the literature, with many examples in the energy decision-making field. An extensive list of examples may be found in Greening and Bernow (2004) or Pohekar and Ramachandran (2004). The latter authors presented a literature review on multicriteria decision-making on sustainable energy planning, and observed that AHP is the most popular technique.

The AHP is especially suitable for complex systems where multiple options and multiple criteria are to be taken into consideration. The computation of a social index for a complex problem, such as the electricity generation options, involves individual judgments and it can be more easily described and analysed using a hierarchical structure. The AHP was selected because of its simplicity and ability to deal with qualitative/subjective data. The method is well suited for group decision making (Lai et al. 2002) and its integration with the Delphi method is also well documented. Using the hierarchical structure, the experts compare the electricity generation options against different criteria. It is possible to recognize conflicts among experts for each element of the hierarchy, how it affects the final ranking and also the consistency of the judgments. The qualitative scale used simplifies the judgement but at the same time allows for the mathematical treatment of the results. The final outcome is the global ranking of the options.

\subsection{Suitability of the Delphi Approach}

The main objective of the Delphi technique is to describe a variety of alternatives and to provide a constructive forum in which consensus may occur (Rayens and Hahn 2000). The three basic conditions of the process are anonymity of the respondents, statistical treatment of the responses and controlled feedback in subsequent rounds.

The anonymity of the answers gives group members the freedom to express their opinion, avoiding possible negative influences due to previous assumed positions, status of the participating experts and reluctance on assuming positions different from the general opinion or from a dominant group. The statistical treatment of the responses allows the assembly of collective information. This phase feature ensures that all the opinions are accounted for the final answer and that these opinions may be communicated to the panel without revealing individual judgments. The controlled feedback ensures that the panel individuals have access to the responses of the whole group as well as their own response for reconsideration. The basic sequence of the Delphi method may be resumed as an interactive questionnaire that is passed around several times in a group of experts, keeping the anonymity of the individual responses. 
As Wright and Giovinazzo (2000) stated, the Delphi is not a statistically representative study but a process of collecting opinions from a group of experts, who from their knowledge and exchange of information may achieve comprehensive opinions on the proposed questions. This issue is also pointed out by Okoli and Pawlowsk (2004), who underlined that the questions that a Delphi study investigates are those of high uncertainty and speculation. Thus a general population or sample might not be sufficiently knowledgeable to answer the questions accurately. Also Alberts (2007) demonstrated the advantages of experts' consultation. In his recent study on how to address wind turbine noise and potential wildlife impacts, the author showed that the participants with insufficient experience were unable to participate effectively in the decision-making process, demonstrating that it can be more productive to seek input from technical experts than to seek consensus from all stakeholders.

For this particular research, the questions addressed are complex and highly subjective. Using a panel of experts with previous knowledge and interest in the matter in question seems to be the most productive way to collect opinions. Also, the structured questionnaire ensures a proper collection of information, in a way that may easily be incorporated in the AHP analysis.

\section{Implementation of the Proposed Methodology}

The proposed methodology was applied for the evaluation of future electricity plans for Portugal. The process started with the identification of the components of the hierarchal structure, namely (1) the electricity generation options that should be included in the analysis and (2) the relevant criteria to consider. Following this, a group of experts was invited to participate in the process and the combination of Delphi and AHP methodologies was used to characterize and systematize the experts' preferences.

\subsection{Selection of Options (Electricity Generation Technologies)}

Portugal is strongly dependent on external energy sources, in particular oil. In 2007, $83 \%$ of the primary energy came from imports, and oil represented about $54 \%$ of the primary energy consumed. The main national resources come from renewable energy sources (RES), especially the hydro sector for electricity production. The electricity and heat production activities accounted for $39 \%$ of the total primary energy consumption, and about $70 \%$ of electricity consumed in Portugal came from imported fuels and from electricity imports from Spain. Electricity production was then the largest consumer of primary energy and the largest consumer of imported energy resources. As the main domestic resource for electricity production 
Table 1 Distribution of installed power and electricity production in mainland Portugal, 2008. Source: (REN 2008)

\begin{tabular}{lcc}
\hline & Installed power $(\mathrm{MW})$ & Electricity production $(\mathrm{GWh})^{\mathrm{a}}$ \\
\hline Thermal power plants & $5,820(39 \%)$ & $23,797(57 \%)$ \\
Large hydro power plants & $4,578(31 \%)$ & $6,436(15 \%)$ \\
Special regime producers & $4,518(30 \%)$ & $11,551(28 \%)$ \\
Total & $14,916(100 \%)$ & $41,784(100 \%)$ \\
\hline
\end{tabular}

${ }^{\mathrm{a}}$ Injected in the public grid

is hydro power, the system is highly dependent on fuel importations and on rainfall conditions. ${ }^{3}$

In 2008, the total electricity consumption reached 53,587 GWh (DGGE 2008). Predictions for the next years indicate that the electricity consumption will continue rising at an average annual rate of $4.3 \%$ between 2009 and 2019. At present, the Portuguese electricity generating system is basically a mixed hydrothermal system. The total installed power reached about 14,916 MW in 2008, distributed between thermal power plants (coal, fuel oil, natural gas and gas oil), hydro power plants and Special Regime Producers (SRP) $)^{4}$, as presented in Table 1.

Based on REN (2008) forecasts, an increase of about $85 \%$ of the total installed electricity generation capacity between 2008 and 2019 may be expected. According to these forecasts, there will be a reduction of both thermal and large hydro power quotas and a large increase of the SRP quota, in relative weight. All the energy sources will grow in absolute terms, with the exception of oil power due to the dismantling of the power plants presently consuming it. Thermal power is expected to increase exclusively due to the growth of the natural gas power groups up to 2015 . After that, REN (2008) scenarios assume mainly new investments in coal and a few investments in natural gas. The growth of the SRP will be mainly driven by the increase of the renewable energy sector, in particular wind. According to these scenarios, the wind sector will achieve about $29 \%$ of the total installed power by 2019 .

The Portuguese strategy for the electricity sector represents a clear effort for the promotion of endogenous resources, reduction of external energy dependency and diversification of supply. The combined growth of coal, natural gas and wind power seem to be fundamental for the accomplishment of these goals. As so, these three technologies have crucial importance for future electricity scenarios and its social sustainability should be evaluated.

\subsection{Selection of Criteria}

The criteria should be able to represent the main social (or non quantifiable) features of the system. From existing literature addressing the social impact of the electricity

\footnotetext{
${ }^{3}$ Own calculations based on DGGE online information (www.dgge.pt, April 2009).

${ }^{4}$ Includes the small hydro generation, the production from other non-hydro renewable sources and the cogeneration.
} 
generation technologies and from discussions with experts in the energy field, the criteria considered relevant were defined.

The public perception of wind power is addressed by several authors for a number of countries or regions. Some examples of research studies on this field include Ek (2005), Wolsink (2007), Manwell et al. (2002) or Bergmann et al. (2006) among many others. Most of the studies identified as positive aspects the renewable characteristic of wind power and the avoided emissions. On the other hand, in most of the publications there is a predominant emphasis on the negative visual impact on the landscape. Other identified negative impacts include the impacts on wildlife, the noise pollution, the unreliability of wind energy supply and the possible financial cost, with particular emphasis on the first two aspects.

Studies addressing the coal and gas power plants' impacts deal mainly with the cost and environmental emissions (see Rafaj and Kypreos 2007 or Söderholm and Sundqvist 2003). The environmental impact usually focuses on the damages caused to health and on the impact on climate change. In the ExternE project (European Commission 1995a,b), the external effects from coal and natural gas power plants were mainly associated with their pollutant emissions and their impact on public and occupational health, agriculture and forests. The noise problem was also pointed out, including operational and traffic impact.

Based on the literature and on the non-structured interviews conducted with Portuguese experts from the academic field, energy consultants, members of environmental associations, environmental public organisms' staff and researchers, a set of non-quantitative criteria were chosen to illustrate the proposed process for the social evaluation of the electricity generation technologies:

1. Noise impact. This impact is often referred on the literature as an important criterion to take into account in the valuation of wind and thermal power plant projects. Noise levels can be measured quantitatively, but the public's perception of the noise impact is highly subjective. The interviews also revealed that this is a critical issue for the Portuguese population and, that most complaints, when existing, are due to the noise impact of the energy projects.

2. Impact on birds and wildlife. The Portuguese experts revealed concerns about this impact, in particular in relation to wind power projects. It is also stressed in most international studies and included in the list of potential disadvantages.

3. Visual impact. According to the interviews, this aspect seems to be still of minor importance in Portugal. However, with the expected increase of wind turbines, people may become more aware of its presence and the aesthetical concerns may become more important. For this reason and also because this is the strongest impact reported in international literature, it was decided to include it in the analysis.

4. The social acceptance. The experts' interviews indicate that public opposition is not a fundamental criterion to take into account during the energy planning process. However, Wolsink (2007), for example emphasised the need to take into consideration public attitude on wind implementation decisions, not only at a general level but also at the local project level and stressed the importance of including the public in decision-making process. Also Cavallaro and 
Ciraolo (2005) support that social acceptability is extremely important since it may heavily influence the amount of time needed to complete the energy project. The public acceptance of a project may not be sufficient to ensure its viability, but represents a clear contribution to its success. This last criterion aims to synthesise the experts' perception of the general social acceptance of the electricity generation alternatives.

As the questionnaire will involve pairwise comparisons, it was decided to limit the number of criteria included, avoiding a long and complex process that might reduce the experts' willingness to participate.

\subsection{Hierarchical Structure Formulation}

The problem was subdivided into a hierarchy, in which the main objective is placed in the top vertex, the criteria placed in the intermediate level and the options placed on the bottom level. Combining the electricity generation option and the previously identified criteria, the hierarchical structure of this particular problem may be represented as in Fig. 2.

Based on this hierarchy tree, the process should follow to the pairwise comparison for the evaluation of the criteria against the overall social ranking objective and for the estimation of the relative performance of each option on each of the criteria, evaluated in a numerical scale. For this particular research, the aim was to address the negative social impact of each generating technology. ${ }^{5}$ For comparison a scale based on Saaty (1980) proposal was used, detailed in Table 2.

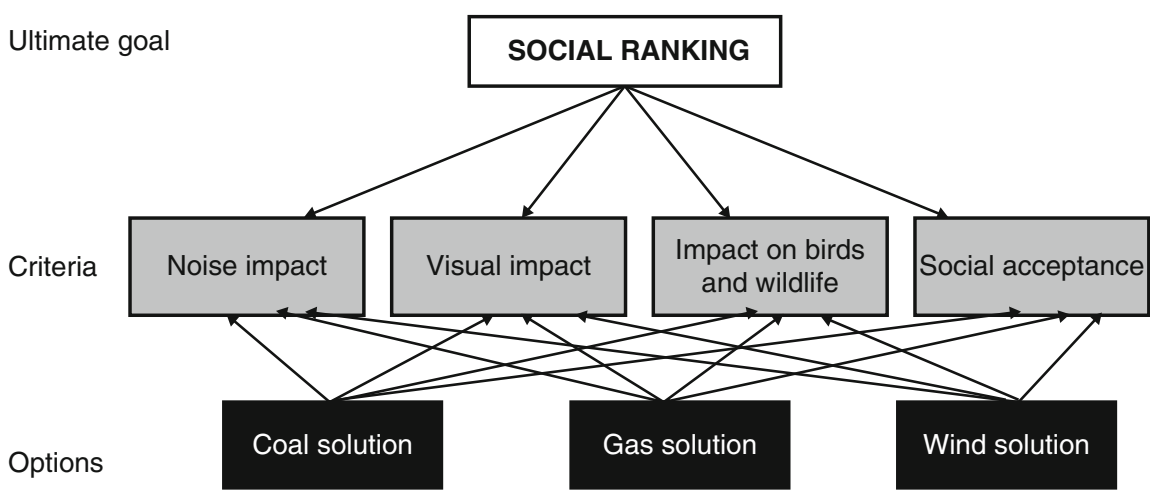

Fig. 2 AHP model for the prioritisation of electricity generation options

\footnotetext{
${ }^{5}$ A particular technology assigned a higher score is considered "worst" from the social point of view than a technology assigned with lower score.
} 
Table 2 Scale preferences used in the pairwise comparison process

\begin{tabular}{lll}
\hline Range & Category & Score \\
\hline Superior & Absolutely superior & 9 \\
& Very strongly superior & 7 \\
& Strongly superior & 5 \\
\multirow{3}{*}{ Equal } & Moderately superior & 3 \\
& Equal & 1 \\
Inferior & Absolutely inferior & $1 / 9$ \\
& Very strongly inferior & $1 / 7$ \\
& Strongly inferior & $1 / 5$ \\
& Moderately inferior & $1 / 3$ \\
\hline
\end{tabular}

Table 3 Pairwise comparison of the alternatives with respect to the noise impact

\begin{tabular}{lccc}
\hline & Coal & Gas & Wind \\
\hline Coal & 1 & 1 & $1 / 3$ \\
Gas & 1 & 1 & $1 / 5$ \\
Wind & 3 & 5 & 1 \\
\hline
\end{tabular}

Table 4 Vector of weights of the alternatives with respect to the noise impact

\begin{tabular}{lc}
\hline & Noise impact \\
\hline Gas & 0.156 \\
Coal & 0.185 \\
Wind & 0.659 \\
$C R$ & 0.0280 \\
\hline
\end{tabular}

To illustrate the kind of results obtained, Table 3 presents a pairwise comparison matrix drawn from the information provided from one of the experts for the evaluation of the three possible generation technologies against noise impact.

The matrix above (Table 3) shows that for this expert the noise impact of coal solution is equal to the noise impact of gas solution. The noise impact of the wind solution is strongly superior to the noise impact of the gas solution and moderately superior to the coal solution. ${ }^{6}$

The pairwise comparisons of each expert were used as input for the AHP analysis using the scale presented in Table 2. The consistency of each comparison matrix was tested and the relative weights of the elements on each level were computed for each expert. For the given example, the vector of weights may be computed along with the consistency ratio, as presented in Table 4.

For this particular expert as far as noise is concerned, gas is the most desirable solution, followed by coal generation plants with wind generation being the least

\footnotetext{
${ }^{6}$ Wind technology is then considered "strongly worst to society" than gas technology, from the noise impact point of view. The same way, wind technology is considered "moderately worst to society" than coal technology, from the noise impact point of view.
} 
desirable. Since the consistency ratio (CR) is below 10\%, then the judgements are considered consistent (Hon et al. 2005; Kablan 2004; Zhong-Wu et al. 2007).

\subsection{Delphi Implementation}

The focus of the Delphi process was on the comparison of three electricity generation technologies (wind, coal and natural gas) in what concerns their major impacts from the social point of view.

The experts were selected from Portuguese universities. With the support of the internet, university staff involved in energy projects or lecturing subjects on this area were identified. Additional experts came from contacts made in the course of the research. Twelve experts who would be appropriate to include in the pilot group were identified. Although all the experts came from the same professional field, they have different opinions and hold a variety of positions for and against each one of the options analysed. The results obtained by using the questionnaire were to be used in the AHP analysis. As so, the questionnaire was written using a pairwise comparison structure and Saaty scale of response, as seen in Table 2. The questionnaire included pairwise comparisons of both the options and the social criteria.

The Delphi implementation involved two iterations and lasted for less than 3 months. Nine of the 12 experts concluded the process, although it was necessary to encourage their involvement through electronic and telephone reminders. The obtained responses were statistically examined using Excel Analysis Toolpack, concerning the frequency distribution and the interquartil range as a measure of consensus. Figure 3 summarises the Delphi process followed to assess experts' opinions on the social impact of the electricity generation technologies in Portugal.

The experts were asked to give their individual view on the pairwise comparison of criteria and options. For the social acceptance criterion, the experts were expected to give their response based on their experience and on what they perceive is the view of the population. In general, the results of the Delphi analysis revealed lack of consensus among experts in some questions. This was not an unexpected outcome due to the subjectivity of the analysed issues and the different awareness and individual perception of the experts. Other studies, such as Shackley and McLachlan (2006), suggest also that there is unlikely to be a wide-ranging consensus amongst energy stakeholders on the desirability of specific future forms of energy generation. However, the results seem to be stable with only few response changes between the first and second round.

\subsection{Determination of Weights for the Electricity Generation Options}

This phase of the research combines the information obtained from the Delphi process with AHP, to convert pairwise comparison of the elements of the hierarchical 


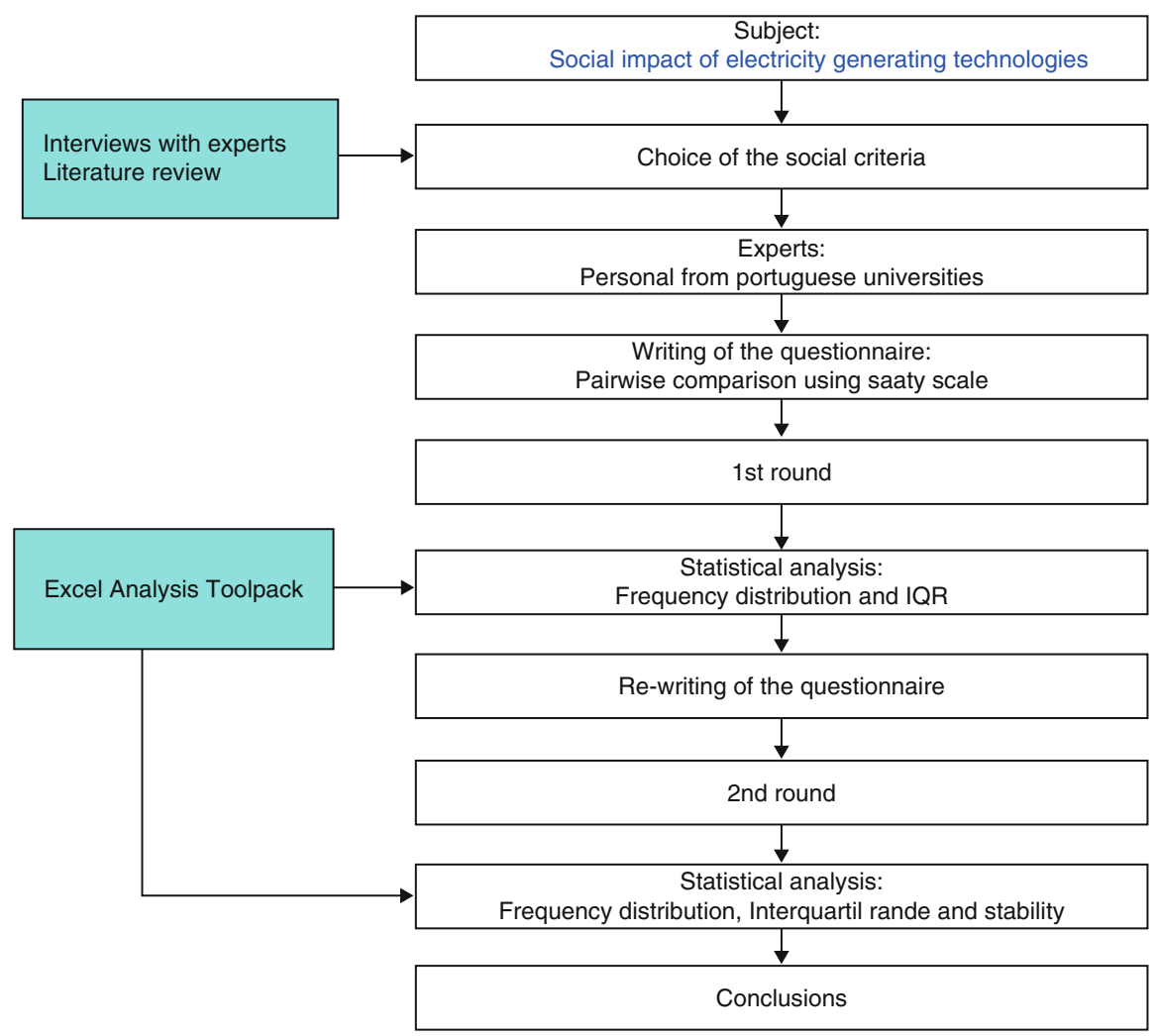

Fig. 3 Delphi process for the social evaluation of electricity generation options

structure in an overall social index, allowing for the ranking of the alternatives. The pairwise comparisons of each expert were used as input for the computation using the scale presented in Table 2. The consistency of each comparison matrix was tested and the relative weights of the elements on each level were computed for each expert.

The group view was represented by the aggregation of each individual's resulting priorities. As the consistency is low for some of the resulting matrixes, only the relative scores of individual matrixes passing the consistency test were included in the aggregation process.

Tables 5 and 6 give the aggregated comparison matrix for the criteria and for the alternatives under each criterion using the geometric mean for the aggregation of the experts' opinions into the final judgement.

The priority vector ranking of criteria with respect to the general goal indicates that social acceptance ranked first followed by impact on birds and wildlife. All these criteria reflect negative aspects for society. For the sake of the consistency of the analysis, social acceptance criterion was computed as the reciprocal corresponding to "social rejection". 
Table 5 Aggregated normalised comparison matrix for the criteria

\begin{tabular}{lc}
\hline Criteria & Priority ranking \\
\hline Impact on birds & 0.293 \\
Noise impact & 0.227 \\
Social acceptance & 0.346 \\
Visual impact & 0.134 \\
\hline
\end{tabular}

Table 6 Aggregated normalised comparison matrix for the alternatives under each criterion

\begin{tabular}{lcccc}
\hline Solution & Impact on birds & Noise impact & Social acceptance & Visual impact \\
\hline Coal & 0.298 & 0.230 & 0.721 & 0.411 \\
Gas & 0.239 & 0.197 & 0.203 & 0.261 \\
Wind & 0.463 & 0.573 & 0.076 & 0.328 \\
\hline
\end{tabular}

Table 7 Aggregated score for the overall social impact of the electricity generation options

\begin{tabular}{lc}
\hline Solution & Social impact \\
\hline Coal & 0.444 \\
Wind & 0.220 \\
Gas & 0.336 \\
\hline
\end{tabular}

According to the group assessment, the wind solution ranked first with respect to the impact on birds and wildlife and to the noise impact. It means that, of the three solutions, wind is the one with strongest negative impacts on birds and wildlife and on noise level. For the other two criteria (visual impact and social acceptance) coal ranked first, meaning that, of the three solutions, coal is the one with strongest negative impacts on visual perception and social acceptance.

Combining the relative weights of the elements at each level of the hierarchical structure, the final scoring of the electricity generation options against the overall social objective is obtained. Table 7 synthesises the overall normalised priorities for the three solutions.

According to the results of the group judgment, the coal solution presents the highest social impact followed by the wind solution. The gas solution seems to be the one ranking better from the global social point of view. The high weight of the social acceptance criterion combined with the low social acceptance of coal comparatively to gas or wind solutions led to a score translating high negative social impact for the coal solution. The gas solution ranked in last for all but social acceptance criteria, resulting in a low overall social impact for this option.

The results clearly demonstrate the importance of the social acceptance criterion to the final ranking. In fact, as may be inferred from Table 6, the differences between the alternatives are particularly remarkable for this criterion. A sensitivity analysis of the results was conducted by withdrawing each criterion from the aggregation procedure. The obtained solutions indicate that the final ranking is exactly the same in sequence when the impact on birds and wildlife, or the noise impact, or the visual impact are excluded from the analysis, although the aggregated score for the overall social impact of each electricity generation option changes. The only exception is 
the social acceptance. If this criterion was excluded from the analysis and all the others remained unchanged, wind power would be the solution with the highest overall social impact, followed by coal and then gas solution.

According to this simple sensitivity exercise, it seems that future work should focus on the social acceptance criterion, both because of the high weight assigned to it and also because of the high differences detected among the social acceptance of each alternative. Further work can decompose and express this criterion in a number of sub-criteria, allowing for a deeper analysis of the results and contributing also to guide the experts in the Delphi process.

\subsection{Social Impact of Future Electricity Generation Scenarios}

The use of AHP and Delphi techniques for the social evaluation of electricity generation technologies was proposed and demonstrated in the last sections. The results obtained can be described by a weight vector characterizing the overall social impact of each one of the technologies considered: coal, gas and wind. However, as seen in Sect. 4.1, future scenarios for the Portuguese electricity system are expected to be based on a mix of different technologies, with coal, gas and wind power playing a key role. To obtain a final ranking of these possible scenarios, the overall social scores of the three alternatives need to be combined by means of a mathematical algorithm. The aim is to get a final index for each possible plan, combining more than one of the available electricity generation technologies. The weights were aggregated using an additive function.

This additive function assumes that the weights assigned to each electricity generation option are constants and satisfy the additive independence, that is these weights do not depend on the relative levels of each option. This additive value model offers a simple way of evaluating multiattribute alternatives. This simplicity makes it widely used in energy planning and policy, as described by Hobbs and Meier (2003).

Equation(1) presents the computation of the average social index (ASI) for each possible electricity plan, depending on the installed power of each electricity generation option and on the weights derived from the AHP:

$$
\mathrm{ASI}=\frac{\sum_{\mathrm{t}} \mathrm{P}_{\text {coal }} \mathrm{W}_{\text {coal }}+\sum_{\mathrm{t}} \mathrm{P}_{\text {gas }} \mathrm{W}_{\text {gas }}+\sum_{\mathrm{t}} \mathrm{P}_{\text {wind }} \mathrm{W}_{\text {wind }}}{\sum_{\mathrm{t}}\left(\mathrm{P}_{\text {coal }}+\mathrm{P}_{\text {gas }}+\mathrm{P}_{\text {wind }}\right)}
$$

where $\mathrm{W}_{\text {coal }}, \mathrm{W}_{\text {gas }}$ and $\mathrm{W}_{\text {wind }}$, represent the overall normalised weights for the coal, gas and wind solutions, described in Table 7 , and $\mathrm{P}_{\text {coal }}, \mathrm{P}_{\text {gas }}$ and $\mathrm{P}_{\text {wind }}$, represent the installed power of coal, gas and wind power plants in each scenario.

To illustrate the process, a set of possible plans for 2017 were drawn from Ferreira (2008). All these plans ensure that the average Kyoto protocol limits imposed to Portugal would not be overcome and are consistent with the objective 
Table 8 Possible electricity plans obtained from Ferreira (2008)

\begin{tabular}{|c|c|c|c|c|c|}
\hline & & Plan 1 & Plan 2 & Plan 3 & Plan 4 \\
\hline \multirow{9}{*}{$\begin{array}{l}\text { Total installed power } \\
\text { (MW) }\end{array}$} & Coal (new) & - & 2,400 & - & 600 \\
\hline & Coal (existing) ${ }^{\mathrm{a}}$ & 1,820 & 1,820 & 1,820 & 1,820 \\
\hline & Natural gas (new) & 5,110 & 1,860 & 5,110 & 3,720 \\
\hline & Natural gas (existing) ${ }^{\mathrm{a}}$ & $2,916^{\mathrm{b}}$ & $2,916^{\mathrm{b}}$ & $2,916^{\mathrm{b}}$ & $2,916^{\mathrm{b}}$ \\
\hline & Wind (new) & 3,225 & 6,514 & 3,225 & 6,500 \\
\hline & Wind (existing) ${ }^{\mathrm{a}}$ & 1,515 & 1,515 & 1,515 & 1,515 \\
\hline & Large hydro & 5,805 & 5,805 & 5,805 & 5,805 \\
\hline & NWSRP & 3,245 & 3,245 & 3,245 & 3,245 \\
\hline & Total & 23,636 & 26,075 & 23,636 & 26,121 \\
\hline \multicolumn{2}{|l|}{ Share of RES (\%) } & 39 & 45 & 39 & 46 \\
\hline \multicolumn{2}{|c|}{ External dependency (\%) } & 65 & 58 & 65 & 57 \\
\hline \multicolumn{2}{|l|}{ Cost $(€ / M W h)$} & 33.627 & 34.961 & 34.365 & 36.950 \\
\hline \multicolumn{2}{|l|}{$\mathrm{CO}_{2}($ ton/MWh $)$} & 0.379 & 0.379 & 0.332 & 0.332 \\
\hline \multicolumn{2}{|l|}{ ASI } & 0.292 & 0.341 & 0.292 & 0.316 \\
\hline
\end{tabular}

${ }^{a}$ Existing at the end of 2006

of reaching $39 \%$ share of electricity produced from RES, as required by Directive 2001/77/EC. Table 8 describes these plans, ${ }^{7}$ detailing the expected total installed power, the share of RES, average cost, average $\mathrm{CO}_{2}$ emissions and ASI.

This analysis allows the decision maker to recognise the differences between the possible electricity generation alternatives and foresee their estimated impacts. The final selection of an electricity strategy for the future depends on the priority that the decision maker chooses to assign to each one of the objectives considered. For example, with respect to the plans described in Table 8, the results reveal that it will be possible to achieve average $\mathrm{CO}_{2}$ emission of 0.379 ton/MWh at a minimal cost of $33.6 € / \mathrm{MWh}$, investing mainly on new natural gas power plants (Plan 1). As natural gas is a socially well accepted solution, the social impact of this strategy should be low, ${ }^{8}$ but the external dependency of the electricity generation sector will remain high. If the decision maker is willing to increase cost by about $4 \%$ (Plan 2), it will be possible to keep $\mathrm{CO}_{2}$ emissions at the same level and the external dependency of the electricity production sector may be reduced by $7 \%$. Also, a more balanced mix between coal and natural gas may be achieved, resulting in considerable advantages from the security of supply point of view. However, as this strategy requires less natural gas power plants and additional investments in new coal and wind power plants, this solution presents a higher ASI reflecting a worst social impact outcome.

\footnotetext{
${ }^{7}$ For additional information on the characterization of the electricity plans and design see Ferreira (2008).

${ }^{8}$ In what concerns the four social criteria analysed: impact on birds and wild life, visual impact, noise level and social acceptance.
} 


\section{Conclusions}

From the work presented, a structured decision making process for the electricity power planning problem can be outlined, combining AHP and Delphi analysis for the social evaluation of future electricity scenarios. The proposed methodology highlights the importance of the social dimension of sustainable planning and recognises that energy decisions should be guided by a context that reflects economic, environmental and social concerns. This distinct and comprehensive referential framework is a useful instrument to distinguish and evaluate different energy strategies and plans, thereby contributing to facilitating explicit discussion and informed decision making.

The combination of social, environmental and economic evaluations will benefit the energy plan formulation, ensuring the robustness of the process and leading to a defensible choice aimed at reducing conflict. However, it is clear that the integration of the social criteria issues on the evaluation of future electricity plans, although being fundamental, is not an easy and consensual task. The suggested tool can be developed as a guideline for providing a structured process to accomplish this task. It can be used for the identification of the relevant social impacts of electricity generation options, for the evaluation of the overall social impact of each electricity generation option and for the assessment of the relative importance of these impacts for the society, giving a measurable interpretation of the expected social impact of future electricity scenarios.

The application of the proposed methodology or the evaluation of future electricity plans in Portugal revealed that the broad diversity of interests and values of the decision makers make consensus difficult to achieve in the energy planning process. It should be highlighted that the difficulty on reaching consensus and consistent results is not a completely unexpected result. Regardless of these difficulties, the proposed tool offers a clear path to explicitly recognise and integrate the social dimension into the electricity planning process, resorting to a structured participatory approach.

According to AHP results, the rank of gas solution was the first in the order of priority, most probably because it represents a compromise solution. It is seen as an electricity generation solution with low environmental problems, which increases its social acceptance over coal. It has also reduced impacts on wildlife, especially when compared to wind power, and lower visual and noise impact than both other alternatives. Coal ranks in last, mainly due to the reduced social acceptance of this alternative. The impact on birds and wildlife and the noise impact are the most severe effects reported for wind power comparatively to both coal and gas solutions. However, the social perception of each technology can be highly volatile and influenced by public groups or opinion makers. The new clean coal technologies and the prices development may easily change this general opinion. Likewise, the spreading of wind power plants may demonstrate that the social impacts of this technology are more or less important than the level assumed by these experts.

Despite the aforementioned various advantages of the proposed approach for the integration of social concerns into electricity power planning, there are a few 
scalability issues that may increase the computational complexities and the number of judgments required. This issue may be particularly relevant when the method is to be used with a large number of criteria or options or when the decision making may involve multiple stages and several decision makers. Therefore, good judgement must prevail to select a proper but limited number of criteria that would make both the Delphi process and the AHP analysis executable. The same holds for the number of experts and decision makers involved in the analysis, although the process could be conducted locally or regionally using the same analytical framework in different stages and, therefore, handling more information in a still efficient way.

The application of the model was presented through a pilot experiment. It is the authors' conviction that this research could still be extended and should be able to accommodate additional data without compromising the resources needed and the efficiency of the process. Two main points must be considered on further research: (1) The increase of the number of experts for enriching the information obtained. This would avoid the influence of each individual on the consensus or stability decision of the group. Further insights' of the subject would be obtained and additional results could be derived from different statistical tools. (2) The inclusion of other social criteria and even the inclusion of quantitative aspects like cost, external dependency and $\mathrm{CO}_{2}$ emissions. Although these last aspects may be measured by quantitative scales, the proposed methodology can give an important contribution on the elicitation of the relative importance of these impacts for the society.

\section{References}

Alberts D (2007) Stakeholders on subject matter experts, who should be consulted. Energy Policy 35(4):2236-2346

Bergmann A, Hanley N, Wright R (2006) Valuing the attributes of renewable energy investments. Energy Policy 34(9):1004-1014

Bruckner T, Morrison R, Wittmann T (2005) Public policy modelling of distributed energy technologies: strategies, attributes, and challenges. Ecol Econ 54(2-3):328-345

Cavallaro F, Ciraolo L (2005) A multicriteria approach to evaluate wind energy plants on an Italian island. Energy Policy 33(2):235-244

Del Río P, Burguillo M (2008) Assessing the impact of renewable energy deployment on local sustainability: Towards a theoretical framework. Renew Sust Energ Rev 12:1325-1344

DGGE (2008) Renováveis. Estatísticas rápidas. December 2008 (in Portuguese). www.dgge.pt

Diakoulaki D, Antunes C, Martins A (2005) MCDA and energy planning. In: Figueira J, Greco S, Erghott M (eds.) Multiple criteria decision analysis - State of the Art survey, int. series in operations research and management science, vol. 78. Springer, pp. 859-897

Dincer I, Rosen M (2005) Thermodynamic aspects of renewables and sustainable development. Renew Sust Energ Rev 9:169-189

Ek K (2005) Public and private attitudes towards "green" electricity: the case of Swedish wind power. Energ Policy 33(13):1677-1689

European Commission (1995a) ExternE. Externalities of Energy, vol. 3. Coal and Lignite, EUR 16522,1995

European Commission (1995b) ExternE. Externalities of Energy, vol. 4. Oil and Gas, EUR 16523, 1995 
European Commission (2003) External Costs. Research results on socio-environmental damages due to electricity and transport, Directorate-General for Research

Ferreira P (2008) Electricity power planning in Portugal: the role of wind energy. PhD Dissertation, University of Minho, Portugal

Ferreira P, Araújo M, O’Kelly M (2004) Including non-financial aspects in project evaluation a survey. 15th Mini-EURO Conference Managing Uncertainty in Decision Support Models, Coimbra, Portugal, 22-24 Sept 2004

G8 Renewable Energy Task Force (2001) Final Report. July, 2001. (http://www.worldenergy.org/ wec-geis/focus/renew/g8.asp)

Greening L, Bernow S (2004) Design of coordinated energy and environmental policies: use of multi-criteria decision making. Energy Policy 32(6):721-735

Hemphill L, McGreal S, Berry J (2002) An aggregating weighting system for evaluating sustainable urban regeneration. J Prop Res 19(4):553-575

Hepbasli A (2008) A key review on exergetic analysis and assessment of renewable energy resources for a sustainable future. Renew Sust Energ Rev 12(3):593-661

Hobbs B (1995) Optimisation methods for electric utility resource planning. Eur J Oper Res 83(1): $1-20$

Hobbs B, Meier P (2003) Energy decisions and the environment: A guide to the use of multicriteria methods, 2nd edn. Kluwer

Hon C, Hou J, Tang L (2005) The application of Delphi method for setting up performance evaluation structure and criteria weights on warehousing of third party logistics. Proceedings of the 35th International Conference on Computers and Industrial Engineering, Istanbul, Turkey, June 2005

Huang J, Poh K. Ang B (1995) Decision analysis in energy and environmental modelling. Energy 20(9):843-855

Jebaraj S, Iniyan S (2006) A review of energy models. Renew Sust Energ Rev 10(4):281-311

Jefferson M (2006) Sustainable energy development: performance and prospects. Renew Energ 31(5):571-582

Kablan M (2004) Decision support for energy conservation promotion: an analytic hierarchy process approach. Energ Policy 32(10):1151-1158

Lai V, Wong B, Cheung W (2002) Group decision making in multiple criteria environment: A case using AHP in software selection. Eur J Oper Res 137(1):134-144

Lehtonen M (2004) The environmental-social interface of sustainable development: capabilities, social capital, institutions. Ecol Econ 49(2):199-214

Liang Z, Yang K, Yuan S, Zhang H, Zhang Z (2006) Decision support for choice optimal power generation projects: Fuzzy comprehensive evaluation model based on the electricity market. Energ Policy 34(17):3359-3364

Limmeechokchaia B, Chawana S (2007) Sustainable energy development strategies in the rural Thailand: The case of the improved cooking stove and the small biogas digester. Renew Sust Energ Rev 11(5):818-837

Loring J (2007) Wind energy planning in England, Wales and Denmark: Factors influencing project success. Energ Policy 35(4):2648-2660

Lund H (2007) Renewable energy strategies for sustainable development. Energy 32(6):912-919

Manwell J, McGowan J, Rogers A (2002) Wind energy explained: Theory, design and application. Willey, England

Nigim K, Munier N, Green J (2004) Pre-feasibility MCDM tools to aid communities in prioritizing local viable renewable energy sources. Renew Energ 29(11):1775-1791

Okoli C, Pawlowsk S (2004) The Delphi method as a research tool: an example, design considerations and applications. Inform Manag 42(1):15-29

Pereira A, Soares J, Oliveira R, Queiroz R (2007) Energy in Brazil: Toward sustainable development? Energ Policy 36(1):73-83

Pohekar S, Ramachandran M (2004) Application of multi-criteria decision making to sustainable energy planning - A review. Renew Sust Energ Rev 8(4):365-381 
Rafaj P, Kypreos S (2007) Internalisation of external cost in the power generation sector: Analysis with Global Multi-regional MARKAL model. Energ Policy 35(2):828-843

Rayens M, Hahn E (2000) Building consensus using the policy Delphi method. Policy Polit Nurs Pract 1(4):308-315

REN (2008) Plano de desenvolvimento e investimento da rede de transporte 2009-2014 (2019) (In Portuguese) (www.ren.pt)

REN (2008) Dados técnicos electricidade 2008. Valores provisórios. (in Portuguese)

Saaty T (1980) The analytic hierarchy process. McGraw Hill, New York

Shackley S, McLachlan C (2006) Trade-offs in assessing different energy futures: a regional multicriteria assessment of the role of carbon dioxide capture and storage. Environ Sci Policy 9: 376-391

Söderholm P, Sundqvist T (2003) Pricing environmental externalities in the power sector: ethical limits and implications for social choice. Ecol Econ 46(3):333-350

Torres Sibille A, Cloquell-Ballester V, Cloquell-Ballester V, Darton R (2009a) Aesthetic impact assessment of solar power plants: An objective and a subjective approach. Renew Sust Energ Rev 13:986-999

Torres Sibille A, Cloquell-Ballester V, Cloquell-Ballester V, Darton R (2009b) Development and validation of a multicriteria indicator for the assessment of objective aesthetic impact of wind farms. Renew Sust Energ Rev 13(1):40-66

Vera I, Langlois L (2007) Energy indicators for sustainable development. Energy 32(6):875-882

Wolsink M (2007) Wind power implementation: The nature of public attitudes: Equity and fairness instead of 'backyard motive. Renew Sust Energ Re 11(6):1188-1207

World Bank (2003) World development report 2003. Sustainable development in a dynamic world - transforming institutions, growth, and quality of life

World Commission on Dams (2001) Dams and development: A new framework for decisionmaking. Overview of the report by the World Commission on Dams. December 2001. (www.poptel.org.uk/iied/docs/drylands/dry_ip108eng.pdf)

World Commission on Environment and Development (1987) Our Common Future. Oxford University Press. (full text available at http://en.wikisource.org/wiki/Brundtland_Report)

Wright J, Giovinazzo R (2000) Delphi-Uma ferramenta de apoio ao planejamento prospectivo. Cadernos de Pesquisas em Administração 1(12):54-65 (in Portuguese)

Zhong-Wu L, Guang-Ming Z, Hua Z, Bin Y, Sheng J (2007) The integrated eco-environment assessment of the red soil hilly region based on GIS-A case study in Changsha City. China Ecol Model 202(3-4):540-546 